\title{
Advances in terrestrial system research in China
}

\author{
WU Shaohong ${ }^{1}$, YIN Yunhe ${ }^{1},{ }^{*}$ ZHENG Du ${ }^{1}$, YANG Qinye ${ }^{1}$, DENG Haoyu ${ }^{1,2}$ \\ 1. Key Laboratory of Land Surface Pattern and Simulation, Institute of Geographic Sciences and Natural \\ Resources Research, CAS, Beijing 100101, China; \\ 2. University of Chinese Academy of Sciences, Beijing 100049, China
}

\begin{abstract}
Land surface is of spatial-temporal heterogeneity. Terrestrial system (TS) comprehensively studies on land surface and physical regionalization objectively describes geographical zonation of the system. China has a vast area with apparent spatial variations in resources and environmental conditions, which highly influence on socio-economic development. In this paper, progress of the TS studies in China is overviewed and research priorities in the near future are prospected. Since the 1950s, China has paid great attention to the TS study as its socio-economic development, and conducted research on physical geographical regionalization, eco-geographical regionalization and comprehensive regionalization. Along with the deepening of global change research, dynamics of TS have been highly concerned. During the studies, methodology has been developed from qualitative research of integration of experts' brainpower gradually to quantitative research based on field observation and experiments of the natural processes, including physical, chemical and biological processes, as well as application of information technology and mathematical simulation. In the near future, TS would combine with the ideology, objectives and key researches of Future Earth program, to focus on the mechanism and regional effects of interaction among land surface elements, the response of TS to global change, the quantitative recognition on regional unit boundary, and the application to TS in sustainable socio-economic development.
\end{abstract}

Keywords: terrestrial system; differentiation rules; global change; sustainable development; China

\section{Introduction}

The physical land surface environment is of spatial-temporal heterogeneity, performing as zonal and azonal differentiation in different scales. The differentiations were generated by three main mechanisms. The first is the shape of the earth, which determining the uneven distribution of the solar radiation energy along the latitude, is the fundamental factor restricting physical geographical zonality. The change of temperature from equator to poles forms corresponding temperature zones on land, as well as the corresponding typical vegetation growth and soil types distribution. The second is the material difference of the surface composition, which could redistribute surface energy budgets and result in great deformation

Received: 2016-03-02 Accepted: 2016-04-15

Foundation: Key Project of National Natural Science Foundation of China, No.41530749

Author: Wu Shaohong, PhD and Professor, specialized in physical geography. E-mail: wush@igsnrr.ac.cn

*Corresponding author: Zheng Du, Professor and CAS Academician, E-mail: zhengd@igsnrr.ac.cn 
or distortion of the zonality pattern. For example, the distribution of land and sea causes the variation of regional moisture conditions with distance from the ocean, which is the same for geographical features and processes. The third is the altitudinal temperature lapse. The mountainous environment and its elements change regularly with altitude, generating altitudinal zonality. Not all regions on land surface have tectonic mountains, therefore, the mountain altitudinal zones distribute discontinuously and are closely related to their basic horizontal zones.

Terrestrial system (TS) is the research about studying land surface syntheses and revealing regional differentiation rules from the viewpoint of system. It takes the geographic space as its object, and moreover, demarcates hierarchically according to the spatial distribution of variables and their combinations (Koeppen, 1931; Huang, 1959; Holdridge, 1967; Bailey, 1983; Zheng, 2008). The TS research aims at systematizing the complicated physical phenomena within a certain region. The natural resources and environmental conditions differ significantly in China, therefore, demarcating regions helps to recognize the spatial differentiation rules of resources and ecosystems comprehensively, to regularize human activities, and to guide local agricultural development (Huang, 1989) and ecological construction reasonably (Zheng, 1999; Fu et al., 2001). Generally, TS has provided a macro framework to guarantee the realization of regional sustainable development (Liu et al., 2005; Zheng et al., 2015).

Since the 1950s, TS has not only promoted the progress in geography and other related subjects, but also made important contributions to socio-economic development. In general, the TS research has three main stages including physical geographical regionalization, eco-geographical regionalization and comprehensive regionalization in China. Moreover, as the impact of global environmental change is much more pronounced, and the contradiction between social development and environmental protection increases significantly, the International Council of Scientific Unions (ICSU), International Social Science Council (ISSC) and other related organizations launched the plan of Future Earth (2014-2023). The Future Earth mainly emphasizes the integration between natural science and social science, for interdisciplinary research of the management decisions on the global environment, hoping to integrate researches on earth system and sustainable development (Future Earth, 2013; Qin, 2014). Therefore, TS particularly its dynamic research is not only a frontier of geography, but also an important way to realize the Future Earth objective and to promote the transition to a sustainable development strategy.

\section{Major stages of the TS research in China}

The TS research in China has undergone several major stages, which are physical geographical regionalization, eco-geographical regionalization, comprehensive regionalization and regional dynamics. The research has developed and enriched continuously from the early sprout of the thoughts.

\subsection{Early sprouted thoughts}

Far in the 5th century B.C., the classic The Tribute of Yu (Yu Gong) summarized the physical geographical situations in China at that time. It undoubtedly was one of the earliest geo- 
graphical works in the world. The Tribute of $Y u$ took the main soil type and soil fertility as important regionalization symbols, and demarcated the ancient China into nine provinces based on mountains, rivers, lakes and seas as the indices (Yang et al., 2014). Later in the Warring States Period, Di Yuan from Guan Zhong (e.g. The Book of Master Guan) classified China's land into first three-level types (plains, hills and mountains) and 25 second-level types (based mainly on ground surface materials and soils), and also with a ranking system and brief descriptions.

\subsection{Physical geographical regionalization in modern times}

The publication of the Climatic Provinces of China by Zhu Kezhen in 1930 (Zhu, 1930) and the Vegetation Regions of China written by Huang Bingwei in 1940 initiated the modern physical geographical regionalization research in China (Huang, 1989).

With the rapid development of China, there had an urgent need to provide a physical geographical regionalization scheme for related departments as reference, since the productions and constructions of agriculture, forestry and animal husbandry must be deployed according to local conditions and obeying natural rules (Huang, 1959). The physical geographical regionalization research in modern times has made substantial progress in solving agricultural problems in China. Systematic and comprehensive physical geographical regionalization research including theory, method and hierarchical scheme have been carried out since the 1950 s in China. In this stage, integrated scientific investigations have been gradually conducted to survey natural conditions and resources over China. Furthermore, various observation networks were established to collect and accumulate basic scientific data and information. Therefore, the physical geographical regionalization research has made considerable progress.

At initial period, main progress included the National Comprehensive Physical Regionalization (Lin, 1954) and the Draft of Physical Geographical Regionalization of China (Luo, 1954). In 1956, the Chinese Academy of Sciences established the physical geographical regionalization committee. The nation-wide integrated physical geographical regionalization was accomplished by the committee after eight sectorial regionalization schemes such as Geomorphological, Climatic, Hydrological, Hydrogeological, Pedological, Vegetational, Zoogeographical and Emtomological regionalizations. The main purpose of the regionalization was for guiding the rational layout of agricultural production. Based on the above exhaustive work, the Integrated Physical Geographical Regionalization of China (First Draft) was issued (Huang, 1959) (Figure 1). As the most detailed and systematic monograph of national physical geographical regionalization at that time, the scheme had enormous influences for China, and had been an important basis for agriculture, forestry, transportation and other relevant departments. Moreover, provincial agricultural regionalization committees had been set up, some of which were still functioning nowadays, reflecting the importance to guide agricultural development according to differentiation rules. In addition, the National Agricultural Integrated Regionalization in China (Qiu, 1986) and Integrated Agro-regionalization of China were also drawn up based on the above publications of physical regionalization of China (Zhou, 1990).

Since then, the national scale researches of physical geographical regionalization have been widely conducted. For example, Ren (1961) proposed a few new opinions such as de- 
marcating index, quantitative evaluation, hierarchical units and nomenclature. Hou (1963) proposed a regional division that aimed at developing agriculture, forestry and animal husbandry. The scheme was practical, with obvious target, but it still had some controversies such as the division of thermal zones. Zhao (1983) designed a relatively new scheme, which combined the lowest regional hierarchy unit with land types, and linked up with each other. In order to guide local plan and agricultural production, Xi et al. (1984) divided regions and described the details of regional physical features, agricultural situations, potential productivities and development directions. Hou (1988) divided China into 20 physical ecological regions including the guidelines for macro agricultural development in each region. In addition, Ren (1982) compiled physical geographical regionalization scheme for China in the 1980s, and illuminated the ways of resource utilization and environmental renovation for each region. Generally, although with different objectives, the researches of this stage have concretized regionalization theories, deepened the understanding of differentiation rules, and furthermore provided essential guidelines for local development and especially agricultural production in China.



Figure 1 Map of Integrated Physical Geographical Regionalization of China (First Draft) (Huang, 1959)

\subsection{Eco-geographical regions}

Along with urgent demands of ecological construction and environmental protection, ecological ideas, principles and methods had been gradually introduced into the TS research (Bailey, 1983, 1996). In China, the eco-geographical regionalization research began since the end of the 1980s (Hou, 1988; Zheng et al., 1999, 2008; Fu et al., 2001).

In this stage, sensitivity, pressure and vulnerability of ecosystem and environment were 
given priorities in the ecological regionalization, and therefore sensitive or vulnerable regions were divided (Fu et al., 2001; Fu et al., 2015). In 2008, the eco-geographical regionalization system was published (Zheng et al., 2008) (Figure 2). The system emphasized the feature and differentiation of land degradation and rehabilitation, as well as ecological protection and construction planning in each eco-geographical zone. Furthermore, it also illuminated the difference, connection and utilization of physical conditions among all regions. Generally, the eco-geographical regionalization system has afforded a macro regional framework for the basic research of physical processes on land surface, and the harmonization of environment, resources and economic development as well. Moreover, it has also provided essential scientific basis for the improvement of potential land productivity, the analysis of land management policy, the introduction and popularization of advanced agricultural technology, the setup and planning of natural reserves, and environmental planning.

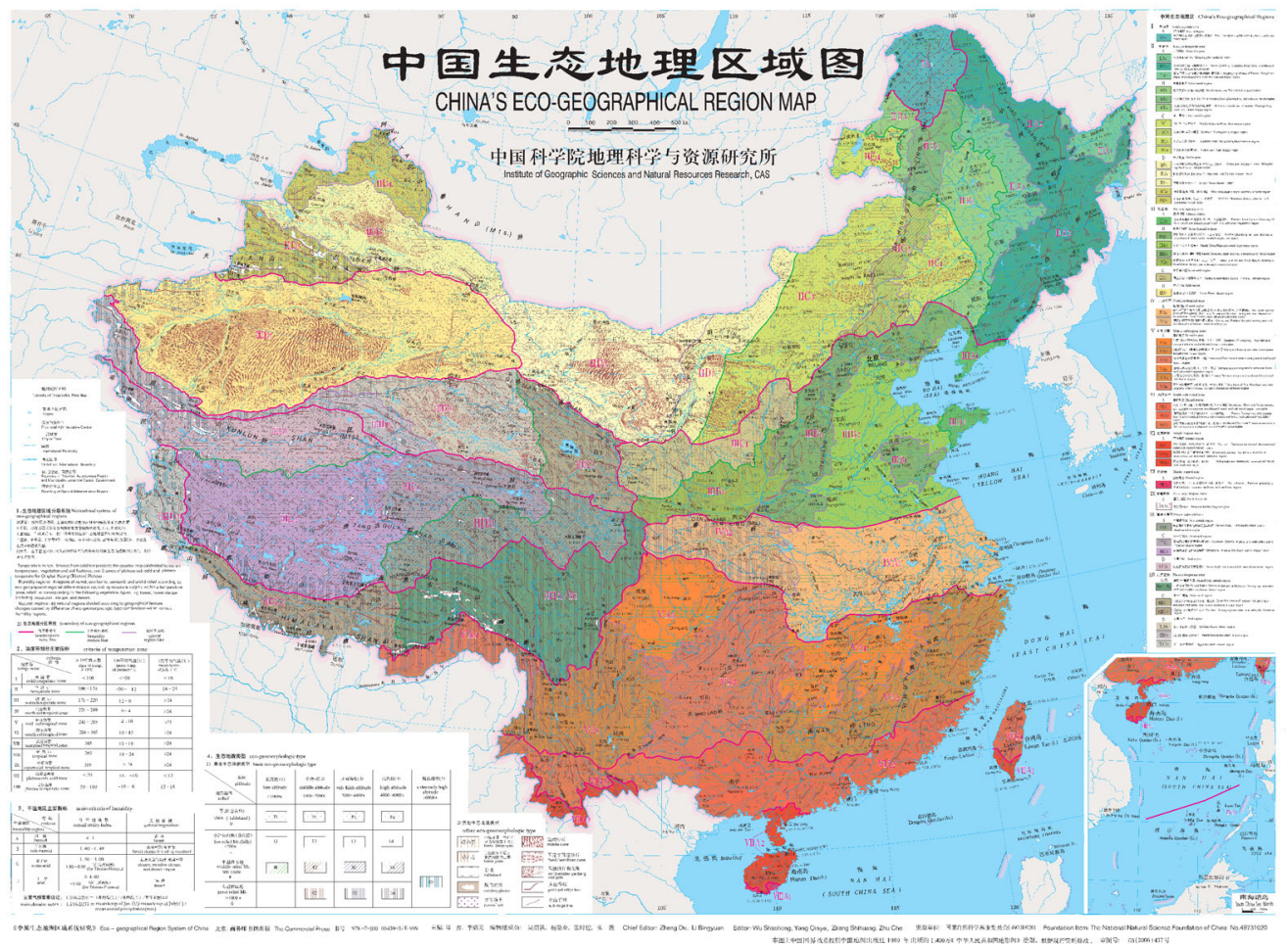

Figure 2 Map of Eco-geographical Regionalization of China (Zheng et al., 2008)

\subsection{Comprehensive regionalization}

With the research progress in earth system science and sustainable development, Professor Huang Bingwei proposed to carry out the comprehensive regionalization research in the end of the 20th-century (Huang, 2003). In his view, there should be a national comprehensive regionalization that takes both the nature and socio-economy into account appropriately, to satisfy the needs of new situation. As indicated by Liu et al. (2004), there had significant changes in China in the past 50 years, mainly include land surface pattern, resources and environmental pattern, and socio-economic development pattern. Meanwhile, the global environmental change and the economic globalization had brought new opportunities and 
challenges to the sustainable development and national security in China. However, the existing regionalization schemes could not completely fit to the new demands of situation. Therefore, the comprehensive regionalization research became essential, which should consider both natural and human factors synthetically and covers both land and sea systems (Liu et al., 2004). A few studies have been successively conducted to explore comprehensive demarcation of regions (Wu, 1998; Zheng et al., 1999; Ge et al., 2003; Wu et al., 2005).

However, the comprehensive regionalization research had difficulties to achieve breakthrough mainly because of absence of explicit direction and index system to demarcate. The major function-oriented zoning has solved the problem by taking the regional functions as the regionalization direction. According to the genetic principle, the major function-oriented zones have constructed the index system, and conducted the suitability evaluation works. Four major function zones of county scale, namely optimized, prioritized, restricted, and prohibited zones, have been proposed (Fan, 2015). These are the positive explorations on the national and regional comprehensive regionalization works, which aim at solving the problems of urban construction, economic development, resource utilization and ecological environment in China. The works had provided a new method for the comprehensive research of the physical and human factors.

\subsection{Regional dynamic research}

During the last century, the human activities (e.g. anthropogenic climate) have caused substantial impacts on natural system (IPCC, 2007; IPCC, 2013), which could be manifested in a short period. Therefore, the key factors of land surface have changed, and furthermore driven TS to change, which have been paid close attention.

Studies on the changes in TS have progressed gradually during the last decade in the 20th century, mostly based on the dominant criteria of TS and in situ observations. For example, the temperature zones in eastern China shifted northward under climate change in the last decades, with significant changes in the north subtropical zone and the warm temperate zone, through analyzing the variations of the accumulated temperatures and days above $10^{\circ} \mathrm{C}$ and the average temperature of the coldest and the warmest month (Sha et al., 2002; Zhao et al., 2002; Ye et al., 2003). Compared with the temperature zone, the humidity zone boundaries varied in a fluctuating way (Yang et al., 2002). During the last 50 years, there was an obvious eastward shift of the boundaries of arid and semi-arid zones in the central part of Northeast China and northern part of North China, and a southward shift of the semi-arid boundary in the south of Shaanxi province and North China (Ma et al., 2005).

In addition, the studies on the response of TS to future climate change had gotten more and more attentions in China too. In the early 1990s, the temperature zone was estimated roughly based on an increment scenario of global temperature (Huang, 1993; Zhao, 1995; Zhao et al., 2002). For example, based on a hypothetical estimation of $3^{\circ} \mathrm{C}$ warming in 2100 , the majority part of cold temperate zone would shift to mid-temperate zone, and the majority part of mid-temperate zone mainly to warm temperate zone (Huang, 1993). Recently, the regionalization dynamic researches have carried out based on climate models and emission scenarios. For example, according to the regional climate models, Wu et al. (2010) projected the future changes of temperature zones, and found a generally northward-shift in the future. In their study, the subtropical zone, warm temperate zone and the northern boundary of pla- 
teau temperature zone would shift significantly with $6.6^{\circ}, 5.3^{\circ}$ and $3.1^{\circ} \mathrm{N}$ in the next 100 years, respectively.

\section{Methods progress in China}

With the rapid development of science and technology, and the increased application of TS in the 20th century, the TS studies have been promoted deeply in China. Methods have developed from qualitative to quantitative by integrating inductive and deductive methods, and combining top-down and bottom-up ways as well. Thus, the objectivity and repeatability of regionalization schemes have been enhanced.

\subsection{Qualitative methods}

During the stage of physical geographical regionalization in the $1950 \mathrm{~s}$, the delimitation methods were mainly qualitative. Generally, the representative qualitative method is expert integration, which is an empirical judgment of scholars on where is the boundary to delimit regions. However, the qualitative methods are usually subjective. For example, the research of integrated physical geographical regionalization in the 1950s aimed at providing scientific basis for the development of agriculture, forestry, husbandry and fishery. Therefore, the main classification principles included: classifying types before regions, emphasizing the contemporary physical geographical characteristics and the mutual relations, and combining zonality and azonality. For zonal classification, the first element to be considered was temperature which could not be altered by human activities easily, and the second was moisture condition which could be changed limitedly. Furthermore, boundaries were determined based on the regional differences of land surface elements including climate, vegetation, landform and soil, and then the quantitative indices to delimit boundaries were sought based on the geographical correlations with the elements (Huang, 1959).

Qualitative methods have the advantages of quickness and accuracy to determine the macro regional patterns. However, at small scale, the expert judgment would be strongly influenced by complex situations. Therefore, significant divergences on the specific problems such as the boundary direction occurred since the reality realization and knowledge backgrounds are different among scholars. For example, how to delimit the north boundary of tropical had introduced abundant discussion among scholars (Zeng et al., 1980; Huang, 1992; Qiu, 1993; Wu et al., 2000).

\subsection{Quantitative methods}

Since the 1980s, the quantitative methods have gradually applied in the TS research to enhance its objectivity and replicability. The key classification indices mainly reflect climate, landform, soil, vegetation, and other physical elements (Huang, 1989). Besides the key indices, indices reflect population, resources, environment, social and economic development level, and ecological management degree, are also involved in the comprehensive regionalization research (Ge et al., 2003). The identification index system of major function-oriented zoning of China comprises nine quantitative indicators (including water resources, land resources, ecological importance, ecological fragility, environmental capacity, disaster risk, economic development level, population concentration and transport superiority) and one 
qualitative indicator of strategic choice (Fan, 2015).

Along with the development of the observing and experimental technologies, remote sensing (RS), global positioning system (GPS) and geographic information system (GIS) technologies (hereafter 3S), the TS studies have progressed significantly, mainly in reflecting regional characteristics and indicating regional boundaries.

Indicators of the eco-geographical regionalization mainly include temperature criteria (e.g. days of temperature $\geqslant 10^{\circ} \mathrm{C}$, accumulated temperature $\geqslant 10^{\circ} \mathrm{C}$, mean temperature of January and July), humidity criteria (e.g. annual aridity index), vegetation and eco-geomorphologic type (Zheng et al., 2008). For example, 220 days of temperature $\geqslant 10^{\circ} \mathrm{C}$ and $4500^{\circ} \mathrm{C}$ of accumulated temperature $\geqslant 10^{\circ} \mathrm{C}$ are two main criteria to delineate temperate zone and subtropical zone. Humidity criteria have been developed from Selianinov heat index, Thornthwaite wetness index to Penman-based aridity index, which are based on more meteorological variables such as radiation, temperature, wind speed, relative humidity and precipitation. Regions with annual aridity index less than 1.0 is usually demarcated as humid zone, 1.0-1.49 as sub-humid zone, 1.5-4.0 as semi-arid zone, and larger than 4.0 as arid zone (Zheng et al., 2008).

Since the 21 st century, as the $3 \mathrm{~S}$ technologies developed and improved, the synthesis and integration of geographical science have got a quantitative scientific basis and an advanced technology assurance (Chen, 2001). At the same time, models and mathematical simulation technologies were gradually applied in the TS research, such as artificial neural network (Li et al., 2003) and wavelet transform method (Li et al., 2008). At present, the TS research has put more emphasis on system ensemble, which focuses on integrating analysis and synthesis, and combining top-down deduction and bottom-up induction methods (Cai, 2010).

\section{Prospects of the TS studies}

Under the framework of global change and the Future Earth, the TS studies should be combined with the concepts, goals and contents of the Future Earth. In order to promote the TS research to a higher level, future highlights include: the interaction mechanism and regional effects of key land surface elements, the dynamic response to global change, the quantitative identification of the boundaries of regional units, and the enhancement of applicability of regionalization system.

\subsection{Interaction mechanism and regional effects of key land surface elements}

The land surface elements, which usually change in a dynamic balance, are driving changes in the physical geographical environment and forming the regional differences of the landscape. At present, the research on the trend and process of key single elements (including water, soil, air, living, etc.) has been relatively mature. However, the comprehensive research of multiple elements is not enough, and the system perspective of research is not clear. Moreover, the interaction of changes of multiple elements should be studied, especially the mechanism of dynamics of land surface pattern influenced by the inter-coupling of key elements. Therefore, future research should focus on the spatial-temporal changes of key elements during the last decades. Especially, we should clarify the impact and mechanism of spatial-temporal change and interactions of key elements on the land surface features, such 
as moisture conditions, heat resources, and land cover. Synergies and differences of key elements are also crucial.

The investigation of interaction mechanism between physical and human elements would provide basis for depicting regional characteristics comprehensively and objectively. In which, the fundamental scientific issues mainly include the coordination of physical and human elements in different regionalization level, and the selection of reasonable index. More researches should be conducted on how the ecosystem and human activities mutually restrict and promote each other. It mainly includes both the impact of human activities on the structure and function of ecosystem, and the feedback of ecosystem responses to human activities.

\subsection{Dynamic response of TS to global change}

Under the global change, the impact of human activities and climate change on land surface process has been more and more significant. At the same time, the vulnerability of physical and human elements and natural-social-economic compound system has varied. Therefore, the land surface pattern has changed accordingly. However, descriptions of land surface pattern were mainly static in order to reflect the average condition of long period. Dynamic response of TS to global change has been seldom conducted deeply. In the future, we should focus on the changing processes and patterns of key land surface elements, the tendency and amplitude of land surface pattern, and the dynamic response of land surface pattern to global change. It helps to reveal the driving mechanism of variations of land surface system, and conduct further research on the evolution of TS.

Usually in the past, long-term time series were thought to be better to represent the "normal" conditions of land surface pattern and could avoid "accident" conditions. However, along with the thorough research of global change, geographer found that changes in land surface elements could possibly lead to dynamic regional pattern under a long period, particularly the last hundred years featured with significant human activities. Such dynamics may have substantial impacts on the resource environment pattern and socio-economic layout. Therefore, it is urgent to study the varied interaction among key land surface elements, and its mechanisms, amplitude and spatial extent. Moreover, the role of the synergies and differences among changes in land surface elements in the regional formation and development of the needs to be revealed comprehensively and quantitatively. Last but not least, the dynamic responses of regionalization system to global change need to be clarified in different time scales from past to future under various socio-economic development scenarios. Recently, this work has received the support from the key project of National Natural Science Foundation of China.

\subsection{Quantitative identification of the boundaries of regional units}

Quantitative methods are advanced for land surface elements. However, these methods could not be fully applied to land surface pattern since TS represents the interaction among different elements. Moreover, the interactions among elements are nonlinear, making their spatial patterns not completely consistent. Therefore, the regional boundary is not simply the summation of several elemental boundaries. As a result, the recognition of regional boundary was usually under debate. Demarcation of land surface pattern needs information technology 
on the premise of theory unity. Synthesizing the expert intelligence, concept analysis, information technology, model application, multidisciplinary integration and other methods, to realize the quantitative recognition of regional unit boundaries, would be a breakthrough of regionalization system research.

\subsection{Enhancement of applicability of regionalization system}

The aims of regionalization system research are to understand natural rules, and to serve practices such as production and ecological construction. The achievements have provided decision-making advice and scientific basis for government and society, and generated great economic and social benefits. The existing researches have played a unique and important role in the national and regional constructions, especially in agricultural production, land investigation and planning, resources investigation and development, productivity layout, environment renovation, regional and urban planning, and nature reserve construction. In addition, the regionalization researches have greatly enhanced their application values and scientific level, and also promoted the development of other disciplines.

Nowadays, along with the orientation of ecological civilization construction, the TS research should pay more attention to resources, ecosystems and environment. Furthermore, researches on the impact and feedback of human activities on environment need to be strengthened, in order to enhance the objectivity and applicability of regionalization systems. It would be benefit for guiding ecological construction and socio-economic sustainability.

\section{References}

Bailey R G, 1983. Delineation of ecosystem region. Environmental Management, 7: 365-373.

Bailey R G, 1996. Ecosystem Geography. New York: Springer-Verlag.

Cai Y L, 2010. New perspectives on physical geography. Geographical Research, 29(1): 1-10. (in Chinese)

Chen S P, 2001. Information and modernization of geography. Scientia Geographica Sinica, 21(3): 193-197. (in Chinese)

Fan J, 2015. Draft of major function oriented zoning of China. Acta Geographica Sinica, 70(2): 186-201. (in Chinese)

Fu B J, Liu G H, Chen L D et al., 2001. Scheme of ecological regionalization in China. Acta Ecologica Sinica, 21(1): 1-6. (in Chinese)

Fu B J, Liu G H, Ouyang Z Y, 2015. Ecological Regionalization in China. Beijing: Science Press. (in Chinese)

Future Earth, 2013. Future Earth Initial Design Report. http://www.futureearth.org/media/future-earth-initialdesign-report.

Ge Q X, Zhao M C, Zheng J Y et al., 2003. Division of the terrestrial system in China: A case study from Huang's theory on terrestrial system science. Scientia Geographica Sinica, 23(1): 1-6. (in Chinese)

Holdridge L R, 1967. Life Zone Ecology. San Jose: Tropical Science Center.

Hou X Y, 1988. Physical Ecological Regionalization and Macro-agricultural Developing Strategy in China. Beijing: The Commercial Press. (in Chinese)

Hou X Y, Jiang S, Chen C D, 1963. Suggestion on the developing direction of agriculture, forestry, animal husbandry, sideline production and fishery in different regions of China. Chinese Science Bulletin, (9): 8-26. (in Chinese)

Huang B W, 1959. Draft of the Integrated Physical Geographical Regionalization of China. Chinese Science Bulletin, 18: 594-602. (in Chinese)

Huang B W, 1989. Outline of the Comprehensive physical geographical regionalization of China. Collected Works 
of Geography, 21: 10-20. (in Chinese)

Huang B W, 1992. Comment on the northern border of tropical zone in China: I. The international definition of tropical zone and sub-tropical zone. Scientia Geographica Sinica, 12(2): 97-104. (in Chinese)

Huang B W, 1993. How to deal with global warming. In: Editorial Committee of Huang Bingwei Collection (ed.). Collections of Huang Bingwei's Sixty Years Comprehensive Work of Physical Geography. Beijing: The Commercial Press, 470-484. (in Chinese)

Huang B W, 2003. Problems on regionalization in the new period. In: Editorial Committee of Huang Bingwei Collection (ed.). Collections of Huang Bingwei's Integrated Research in Physical Geography. Beijing: The Commercial Press, 350-352. (in Chinese)

Koeppen W, 1931. Grundriss der Klimakunde. Berlin: Walter de Gruyter.

Li S C, Zhao Z Q, Gao J B, 2008. Identifying eco-geographical boundary using spatial wavelet transform. Acta Ecologica Sinica, 28(9): 4313-4322. (in Chinese)

Li S C, Zheng D, 2003. Applications of artificial neural networks to geosciences: Review and prospect. Advance in Earth Science, 18(1): 68-76. (in Chinese)

Lin C, 1954. Outline of the physical geographical regionalization. Acta Geographica Sinica, 20(4): 395- 418. (in Chinese)

Liu Y H, Ge Q S, Zhang X Q, 2004. Thoughts about the development for the research of human dimensions on global environmental change in China. Advances in Earth Science, 19(6): 889-895. (in Chinese)

Liu Y H, Zheng D, Ge Q S et al., 2005. Problems on the research of comprehensive regionalization in China. Geographical Research, 24(3): 321-329. (in Chinese)

Luo K F, 1954. Draft of the physical geographical regionalization of China. Acta Geographica Sinica, 20(4): 379-394. (in Chinese)

Ma G Z, Fu C B, 2005. Decadal variations of arid and semi-arid boundary in China. Chinese Journal of Geophysics, 48(3): 519-525. (in Chinese)

Qin D H, 2014. Climate change science and sustainable development. Progress in Geography, 33(7): 874-883.

Qiu B J, 1986. A scheme of national agricultural integrated regionalization in China. Journal of Henan University (Natural Science), 16(1): 21-28. (in Chinese)

Qiu B J, 1993. The northern border of tropical zone in China. Scientia Geographica Sinica, 13(4): 297-306. (in Chinese)

Ren M E, 1982. Outline of Chinese Physical Geography. Rev. ed. Beijing: The Commercial Press, 1-412. (in Chinese)

Ren M E, Yang R Z, 1961. Physical geographical regionalization in China. Acta Geographica Sinica, 27: 66-74. (in Chinese)

Sha W Y, Shao X M, Huang M, 2002. Climate warming and its impact on natural regional boundaries in China in the 1980s. Science in China: Series D, 32(4): 317-326. (in Chinese)

Wu S H, 1998. The Basic Designation of integrated zonation: Case study of Chaidam basin. Geographical Research, 17(4): 367-374. (in Chinese)

Wu S H, Liu W D, 2005. An integrated approach to classification of territorial systems: A case study of Tibetan Plateau. Geographical Research, 24(2): 169-177. (in Chinese)

Wu S H, Zheng D, 2000. New recognition on boundary between tropical and subtropical zone in the middle section of eco-geographic System. Acta Geographica Sinica, 55(6): 689-697. (in Chinese)

Wu S H, Zheng D, Yin Y H et al., 2010. Northward-shift of temperature zones in China's eco-geographical study under future climate scenario. Journal of Geographical Sciences, 20(5): 643-651.

Xi C F, Zhang J M, Qiu B J et al., 1984. Outline of Physical Regionalization of China. Beijing: Science Press. (in Chinese)

Yang J P, Ding Y J, Chen R S et al., 2002. The interdecadal fluctuation of dry and wet climate boundaries in China in recent 50 years. Acta Geographica Sinica, 57(6): 655-661. (in Chinese)

Yang W H, Yang Q Y, 2014. History of Geography in China (Ancient Volume). Nanning: Guangxi Education Press. (in Chinese) 
Ye D Z, Jiang Y, Dong W J, 2003. The northward shift of climatic belts in China during the last 50 years and the corresponding seasonal responses. Advances in Atmospheric Sciences, 20(6): 959-967.

Zeng Z X, Liu N W, Li G Z et al., 1980. Discussion on tropical border of China. Acta Geographica Sinica, 35(1): 87-91. (in Chinese)

Zhao M C, 1995. Impact of $\mathrm{CO}_{2}$ multiplication on the differentiation of physical zones and the potential agricultural productivity in China. Journal of Natural Resources, 10(2): 148-157. (in Chinese)

Zhao S Q, 1983. A new scheme for comprehensive physical regionalization in China. Acta Geographica Sinica, 38(1): 1-10. (in Chinese)

Zhao X Y, Zhang H Y, Wan J, 2002. The impact of climatic change on the climate zones in the Qinghai-Tibetan Plateau. Scientia Geographica Sinica, 22(2): 190-195. (in Chinese)

Zheng D, Fu X F, 1999. A preliminary study on issues of integrated geographical regionalization Scientia Geographica Sinica, 19(3): 193-197. (in Chinese)

Zheng D, Yang Q Y,Wu S H et al., 2008. China's Ecogeographical Regionalization Research. Beijing: The Commercial Press. (in Chinese)

Zheng D, Yang Q Y, 2015. Review and prospects: Geography in China since 1950s. Science, 67(4): 29-33. (in Chinese)

Zheng D, 1999. A Study on the Eco-geographic Regional System of China. Cambridge: FAO FRA2000 Global Ecological Zoning Workshop.

Zhou L S, She Z X, 1990. Agricultural geography and land utilization. In: Recent Development of Geographical Science in China. Beijing: Science Press, 29-40. (in Chinese)

Zhu K Z, 1930. Climatic provinces of China. Geographical Journal, 3(2). (in Chinese) 